\title{
Simulation-aided characterization of a versatile water-based condensation particle counter for atmospheric airborne research
}

\author{
Fan Mei ${ }^{1}$, Steven Spielman ${ }^{2}$, Susanne Hering ${ }^{2}, J_{i a n}$ Wang $^{3}$, Mikhail S. Pekour ${ }^{1}$, Gregory Lewis ${ }^{2}$, Beat Schmid ${ }^{1}$, \\ Jason Tomlinson $^{1}$, and Maynard Havlicek ${ }^{4}$ \\ ${ }^{1}$ Pacific Northwest National Laboratory, Richland, WA 99352, USA \\ ${ }^{2}$ Aerosol Dynamics Inc., Berkeley, CA 94710, USA \\ ${ }^{3}$ Department of Energy, Environmental \& Chemical Engineering, Washington University in St. Louis, \\ St. Louis, MO 63130, USA \\ ${ }^{4}$ TSI Incorporated, Shoreview, MN 55126, USA
}

Correspondence: Fan Mei (fan.mei@pnnl.gov)

Received: 3 September 2021 - Discussion started: 10 September 2021

Revised: 28 October 2021 - Accepted: 31 October 2021 - Published: 23 November 2021

\begin{abstract}
Capturing the vertical profiles and horizontal variations of atmospheric aerosols often requires accurate airborne measurements. With the advantage of avoiding health and safety concerns related to the use of butanol or other chemicals, water-based condensation particle counters have emerged to provide measurements under various environments. However, airborne deployments are relatively rare due to the lack of instrument characterization under reduced pressure at flight altitudes. This study investigates the performance of a commercial "versatile" water-based condensation particle counter (vWCPC, model 3789, TSI, Shoreview, MN, USA) under various ambient pressure conditions (500$920 \mathrm{hPa}$ ) with a wide range of particle total number concentrations $\left(1500-70000 \mathrm{~cm}^{-3}\right)$. The effect of conditioner temperature on vWCPC 3789 performance at low pressure is examined through numerical simulation and laboratory experiments. We show that the default instrument temperature setting of $30^{\circ} \mathrm{C}$ for the conditioner is not suitable for airborne measurement and that the optimal conditioner temperature for low-pressure operation is $27^{\circ}$. Under the optimal conditioner temperature $\left(27^{\circ}\right)$, the $7 \mathrm{~nm}$ cut-off size is also maintained. Additionally, we show that insufficient droplet growth becomes more significant under the low-pressure operation. The counting efficiency of the vWCPC 3789 can vary up to $20 \%$ for particles of different chemical compositions (e.g., ammonium sulfate and sucrose particles). However, such variation is independent of pressure.
\end{abstract}

\section{Introduction}

Atmospheric aerosol particles are one of the key components of the atmosphere. The currently known ambient aerosol has a size range over several magnitudes and consists of complex chemical compositions, which vary with size, origin, age, and atmospheric processing. This tiny but complicated particulate matter plays a remarkable role in climate change (Seinfeld et al., 2016) and human health (Anderson et al., 2020; Lighty et al., 2000; Pöschl, 2005). To understand the variation of atmospheric aerosol and its production, distribution, and evolution paths, Friedlander $(1970,1971)$ introduced a conceptual framework for characterizing instruments used for aerosol measurements. Following this framework, the size distribution and number concentration of atmospheric aerosol particles are detected through electrostatic methods and condensational growth. The latter approach is the only technique available for detecting uncharged sub-50 nm particles. Consequently, it has become the dominant technique for assessing the integrated concentration of particles larger than a minimum size.

Since Paul-Jean Coulier and John Aitken published their observations dealing with the role of a fine airborne particle in the vapor condensation process in 1875 and 1880 separately (Spurny, 2000), the need to understand the phenomena has inspired the development of several particle counting instruments and led to various methods to quantify their performance under different operating conditions (Kangasluoma 
and Attoui, 2019; McMurry, 2000a, b). Several reviews have discussed the development of this technique in atmospheric aerosol measurements (Curtius, 2006; Kerminen et al., 2018; Kulmala et al., 2004; McMurry, 2000b). McMurry (2000a) divided the history of condensation nucleus counters into two main sections through the end of the 20th century - the development of expansion-type instruments and steady-flow condensation nucleus counters. Sem (2002) describes the designs of three commercial condensation particle counters (CPCs) and characterizes the particle diameter with $50 \%$ detection efficiencies of a TSI CPC (3025A, 3022A, and 3010). Two recent comprehensive reviews by Kangasluoma and Attoui (2019) and Kangasluoma et al. (2020) focus on developing instruments that can measure the particle size distribution down to the size of large molecules. Kangasluoma et al. (2020) provide an in-depth review of the effort to advance the technology toward sub- $10 \mathrm{~nm}$ size distribution measurements, summarize the current understanding of the characteristics of several systems, and identify instrumental limitations and potential advances for accuracy improvement in sub-3 nm particle counting.

In general, an airborne CPC operates by the same principle as standard ground-based CPCs discussed above. It is essential to allow sufficient supersaturation generated inside the condenser for a continuous flow CPC as discussed in this paper. Previous studies have described the required modifications of a commercial CPC for aircraft operation and demonstrated how to characterize such sensors under low operating pressures down to 150-200 $\mathrm{hPa}$ (Hermann et al., 2005; Hermann and Wiedensohler, 2001; Schröder and Ström, 1997). In the effort to capture the rapid change in the particle concentration from the boundary layer to the stratosphere, the nucleation mode aerosol size spectrometer (NMASS) has been used on research aircraft since 1999. A comprehensive description of the NMASS, its uncertainties under laboratory studies, and operation during the Atmospheric Tomography (ATom) mission was published in 2018. Two NMASSs were comprised of 10 parallel CPCs (five for each NMASS) operating at an internal pressure of $120 \mathrm{hPa}$. They measured the size distribution between 3 and $60 \mathrm{~nm}$ and provided a robust analytical foundation to probe the new particle formation event globally (Brock et al., 2019; Williamson et al., 2018).

Although most CPCs use butanol vapor to grow the aerosol particles, researchers have noticed that the working fluid plays a critical role in determining the size detection limits, as the vapor properties affect how the vapor condenses upon the particle to enlarge its size for detection. Stolzenburg and McMurry (1991) first described the effect of working fluid on size-dependent activation efficiencies with the laminar flow ultrafine condensation particle counter, then theoretically described the effect of the working fluid. Experimental studies by Iida et al. (2009) complemented their theory. Magnusson et al. (2003b) concluded that working fluids with high surface tension (such as water and glycerol) could lead to a smaller activation size and reduce the lower size detection limit in the CPCs. For airborne CPCs, 1-butanol and FC43 (Hermann et al., 2005) are used as a working fluid, and FC-43 shows better performance below $200 \mathrm{hPa}$. As a working fluid, water avoids the health and safety concerns of butanol or other chemicals. Over the last few decades, mixingtype water-based condensation systems have been used to capture particles for online chemical speciation instruments (Khlystov et al., 1995) and high-flow condensation particle counting (Parsons and Mavliev, 2001).

Additionally, water-based CPCs reduce the requirement of chemical storage, maintenance effort, and ventilation system and eliminate water condensation and absorption into alcohol working fluids during operation in humid environments (Liu et al., 2006). However, due to a mass diffusivity of water that is 3 times higher compared to butanol, it is very challenging to use water as the condensing fluid in the above thermally diffusive laminar flow CPC. Therefore, the measurement principle has to be changed (Hering et al., 2005). Hering and Stolzenburg (2005) introduced the concept of a warm, wet-walled condenser for water-based condensational growth. The first implementation of this concept was the twostage water CPC (Hering et al., 2005). The performance of several versions of this two-stage water-based CPC was intensively evaluated in the 21st century (Biswas et al., 2005; Hakala et al., 2013; Hering et al., 2005; Iida et al., 2008; Keller et al., 2013; Kupc et al., 2013; Kurten et al., 2005; Liu et al., 2006; Mordas et al., 2008; Petaja et al., 2006). In 2014, Hering and coworkers further improved the laminar flow water CPC with a third stage to moderate the temperature profile between the growth tube and optics (Hering et al., 2014). This advanced design enables the capture of water vapor by the third moderator stage such that conditions inside the instrument can be self-sustaining with regard to water consumption under moderate to high relative humidity (Hering et al., 2019; Kangasluoma and Attoui, 2019). This feature has been commercialized in the MAGIC CPC (Moderated Aerosol Growth with Internal water Cycling, ADI). This concept also enables a higher temperature for the second "initiator" stage, providing supersaturation can be created between the conditioner and initiator, and leads to the activation of $1 \mathrm{~nm}$ particles without homogeneous water droplet formation (Hering et al., 2017; Kangasluoma and Attoui, 2019). It further allows flexibility in operating temperatures and a lower detection threshold, and hence it has been named the "versatile" water CPC, or vWCPC. The vWCPC has been commercialized by TSI as the model 3789.

Many field deployments confirm that the water-based CPC has performance comparable to a butanol-based CPC in terms of cut-off size and detection efficiency when examining urban pollution and diesel combustion aerosol (Franklin et al., 2010; Jeong and Evans, 2009; Kaminsky et al., 2009; Keller et al., 2013; Lee et al., 2013; Sharma et al., 2011; Tsang et al., 2008). Based on these promising research re- 
sults, it is desirable to explore the advanced water-based CPC for airborne measurements.

Airborne aerosol measurements provide researchers with in situ atmospheric properties across various spatial scales up to thousands of kilometers. However, it also creates design and characterization challenges due to the rapid change in environmental conditions. The pressure dependency of the counting efficiency of non-water-based CPCs has been explored in several studies, and a lower cut-off diameter of the CPCs usually increased with the decrease in the operating pressure (Hermann et al., 2005; Hermann and Wiedensohler, 2001; Seifert et al., 2004; Weigel et al., 2009). However, our literature research shows no records about the water-based CPC being evaluated under low-pressure conditions. Thus, this study characterizes a vWCPC 3789 and its counting efficiency changes under such low-pressure conditions. The current simulation was highly nonlinear for the pressures lower than $500 \mathrm{hPa}$, and the returned solution failed to converge. In addition, we observed inconsistent behavior in one of three model 3789 vWCPCs we tested. Thus, this paper focuses on the measurements and modeling that were done over the pressure range from 500 to $1000 \mathrm{hPa}$. This pressure range also spans an altitude of $6000 \mathrm{~m}(\sim 20000 \mathrm{ft}$.), which is the upper limit for most drone and balloon operations due to FAA restrictions. We examined the $7 \mathrm{~nm}$ configuration rather than the $2 \mathrm{~nm}$ configuration because the equilibrium water vapor pressure at the maximum temperature in the $2 \mathrm{~nm}$ configuration exceeds $500 \mathrm{hPa}$. A three-stage operating temperature profile simulation was carried out to understand the supersaturation profile inside the water-based condensational growth tube and guide the optimization of the operation setting. A previously developed particle growth model was used to evaluate the pressure change effect on aerosol particle activation and droplet growth. A simplified theoretical analysis is presented to evaluate effects associated with high particle concentrations. Data at low pressures were obtained using a monodispersed aerosol of various chemical compositions compared to a CPC operated at atmospheric pressure and a parallel aerosol electrometer at low pressure.

\section{Materials and methods}

\subsection{Instrument description and modification}

The vWCPC 3789 tested in this study uses a three-stage growth tube, as described by Hering et al. (2017). A single tube with a $6.3 \mathrm{~mm}$ i.d. is lined with a wet, porous wick. It has three temperature regions, referred to as the conditioner, initiator, and moderator, with lengths of 73, 30, and $73 \mathrm{~mm}$, respectively. The aerosol flow is $0.3 \mathrm{~L} \mathrm{~min}^{-1}$. The vWCPC 3789 operates in single-particle count mode up to $2 \times 10^{5} \mathrm{~cm}^{-3}$. The manufacturer provides two default cutoff diameter settings: 2 and $7 \mathrm{~nm}$ based on the characteristics by Kangasluoma et al. (2017) using particles from a heated tungsten wire in nitrogen flow. For the $7 \mathrm{~nm}$ configuration tested here, the factory default temperature settings of the walls of the conditioner, initiator, and moderator regions are $T_{\text {cond }}=30^{\circ} \mathrm{C}, T_{\text {ini }}=59^{\circ} \mathrm{C}$, and $T_{\text {mod }}=10^{\circ} \mathrm{C}$.

Several modifications were made to the unit in this study because the commercially available vWCPC 3789 is not designed for low-pressure applications, as shown in Fig. 1. First, the testing vWCPC 3789 was tested to ensure it is vacuum-tight. Therefore, the make-up flow port and exhaust port were blocked during the vacuum-tight check. In addition, the water-fill bottle was connected during the vacuumtight test and low-pressure operations. This step guarantees the instrument operates appropriately under conditions of a significant positive difference between ambient and internal pressures, which mimic the characteristic of the high-altitude operation on an aircraft with a pressurized cabin. Secondly, the vWCPC 3789 monitors the inlet pressure, orifice pressure, and nozzle pressure during the operation. Thus, we connected the ambient pressure port and inlet pressure port to the low-pressure manifold, which prevented triggering the warning and error indicator. Thirdly, we added pressure transducers (Baratron 722B, MKS Instruments. Inc., Andover, MA, USA) to the vWCPC 3789 inlet and the exhaust lines. Finally, when we operated with $1.5 \mathrm{~L} \mathrm{~min}^{-1}$ inlet aerosol flow, we blocked the make-up flow port. However, we focused on $0.6 \mathrm{~L} \mathrm{~min}^{-1}$ inlet aerosol flow in this study. Therefore, when we operated with $0.6 \mathrm{~L} \mathrm{~min}^{-1}$ aerosol inlet flow, $0.9 \mathrm{~L} \mathrm{~min}^{-1}$ flow from the exhaust line was filtered, passed through a flow buffer, and then made up the $1.5 \mathrm{~L} \mathrm{~min}^{-1}$ vacuum flow. Note that under both operating conditions, the aerosol flow passing the condensation tubing and optical particle detector is $0.3 \mathrm{Lmin}^{-1}$.

\subsection{Experimental characterization setup}

The low-pressure calibration setup of the vWCPC 3789 is shown in Fig. 2. Ammonium sulfate was the primary material for this study and was dissolved into deionized water for aerosol generation using atomization techniques. The water-insoluble chemicals, such as humic acid and oleic acid, were atomized from a water suspension after at least 10 min of ultrasonic aided mixing. The properties of the other tested aerosol particles are included in Table S1 in the Supplement. The tested particles selected in this study were commonly used for previous CPC characterization (Hering et al., 2014, 2005; Kangasluoma et al., 2017). To increase the aerosol number concentration for particles less than $30 \mathrm{~nm}$, polydisperse ammonium sulfate (AS) aerosols were also passed through a tube furnace generator (Lindberg/Blue, Thermal Scientific, TX, USA) to shift the size distribution to a smaller size. Polystyrene latex (PSL) particles were generated through an atomizer. After passing a dilution system, the aerosol particles were size-selected by a differential mobility analyzer (DMA, TSI 3081) using a soft $\mathrm{x}$-ray neutralizer (TSI, advanced aerosol neutralizer 


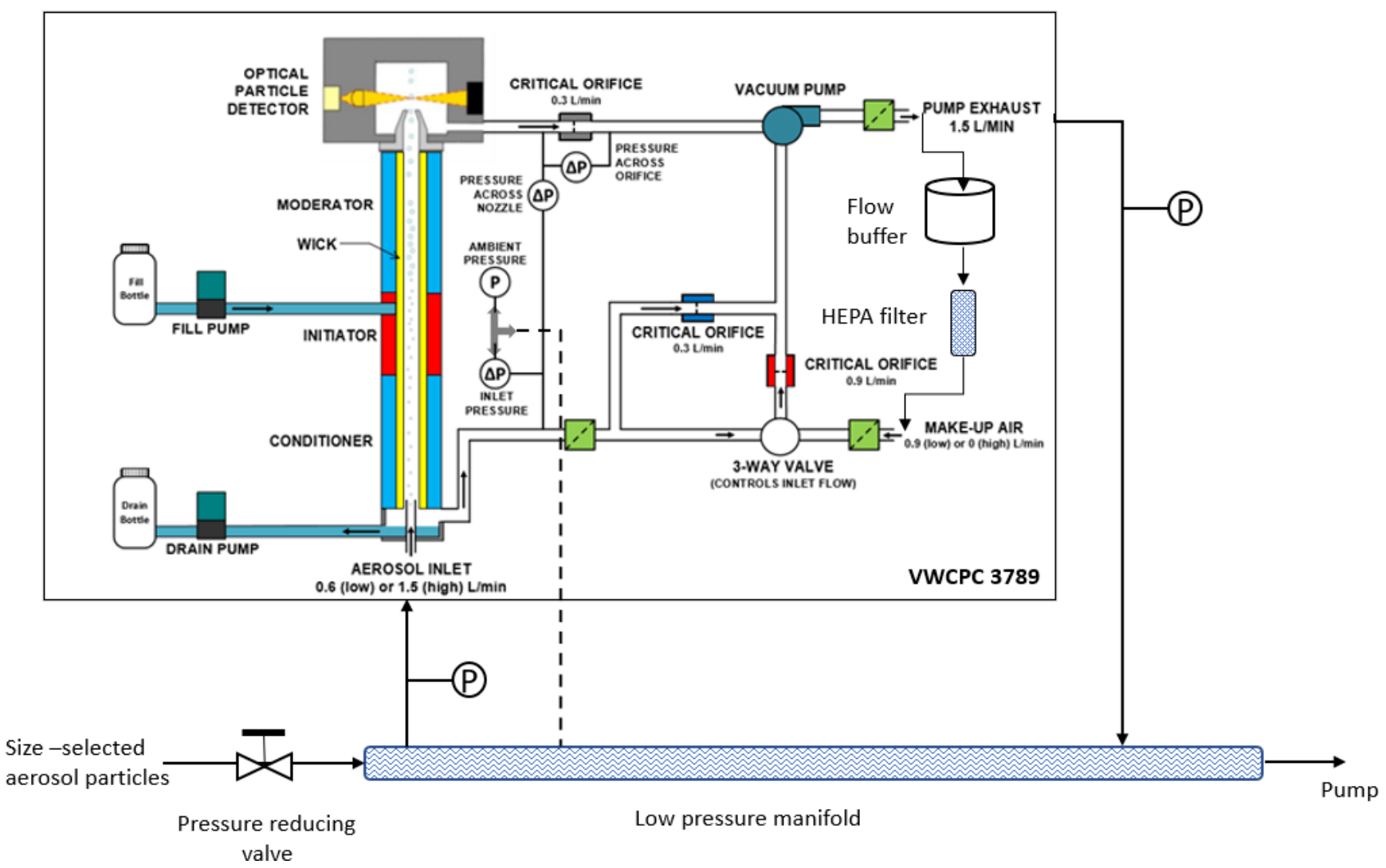

Figure 1. Schematic of the modified vWCPC 3789 sensors and flow system (TSI Incorporated, 2019).

3088). The operating pressure was reduced by a constant pressure inlet (DMT) to simulate different flight-level pressures $(500-1000 \mathrm{hPa})$. For the counting efficiency determination, two reference sensors were used. One reference sensor was a CPC 3775 (TSI, butanol-based, $50 \%$ cut-off diameter is $4 \mathrm{~nm}$ ), which was connected directly to the monodisperse flow after the DMA and operated at a $0.3 \mathrm{~L} \mathrm{~min}^{-1}$ flow rate under atmospheric pressure. Its inlet aerosol flow rate was $0.3 \mathrm{~L} \mathrm{~min}^{-1}$. The other sensor, an aerosol electrometer (A.E. 3068B, TSI, Shoreview, MN, USA), was operated in parallel with the vWCPC 3789 under low-pressure conditions. Both the vWCPC 3789 and A.E. were run at $0.6 \mathrm{~L} \mathrm{~min}^{-1}$ inlet flow with matched tubing lengths to ensure equal diffusive particle loss in the aerosol pathway. The DMA's sheath flow was typically $20 \mathrm{~L} \mathrm{~min}^{-1}$, resulting in a sheath-to-aerosol flow ratio and a non-diffusive mobility resolution of 13 .

\subsection{Numerical simulation}

Numerical simulations of the temperature and humidity profiles and the particle growth were calculated for the geometry of the vWCPC 3789 described above using the methods published by Hering's group (Hering et al., 2014; Lewis and Hering, 2013). The assumption and equations used for the simulation are included in the Supplement. More details are dis- cussed in Sect. 3.2. To summarize the methodology, first, the temperature and humidity profiles were computed using the finite-element modeling software COMSOL Multiphysics ${ }^{\circledR}$ (https://www.comsol.com, COMSOL AB, Stockholm, Sweden; last access: 27 July 2021). Next, the particle growth, temperature, and humidity profiles were calculated using a numerical model developed by Lewis and Hering (Lewis and Hering, 2013) written in Igor Pro (WaveMetrics, Beaverton, OR).

The configuration in the Hering group's research (Hering et al., 2014) is different from the vWCPC 3789 . Hering's WCPC consists of a $4.6 \mathrm{~mm}$ i.d. tube extending through a $154 \mathrm{~mm}$ conditioner, a $76 \mathrm{~mm}$ initiator, and a $100 \mathrm{~mm}$ moderator, with a design flow rate of $1.5 \mathrm{~L} \mathrm{~min}^{-1}$. Their simulation results suggest that the three-stage configuration is superior in decreasing the amount of water vapor and lowering the particle loss and variation in detection and collection, avoiding the side effect of heating the flow. With this "moderated" approach, a short, warm, wet-walled initiator provides sufficient water vapor for activation, followed by a cool-walled moderator for particle growth. A recent simulation study (Bian et al., 2020) confirmed the Hering group's finding with different temperature settings. In general, enhancing the temperature difference between the initiator and 


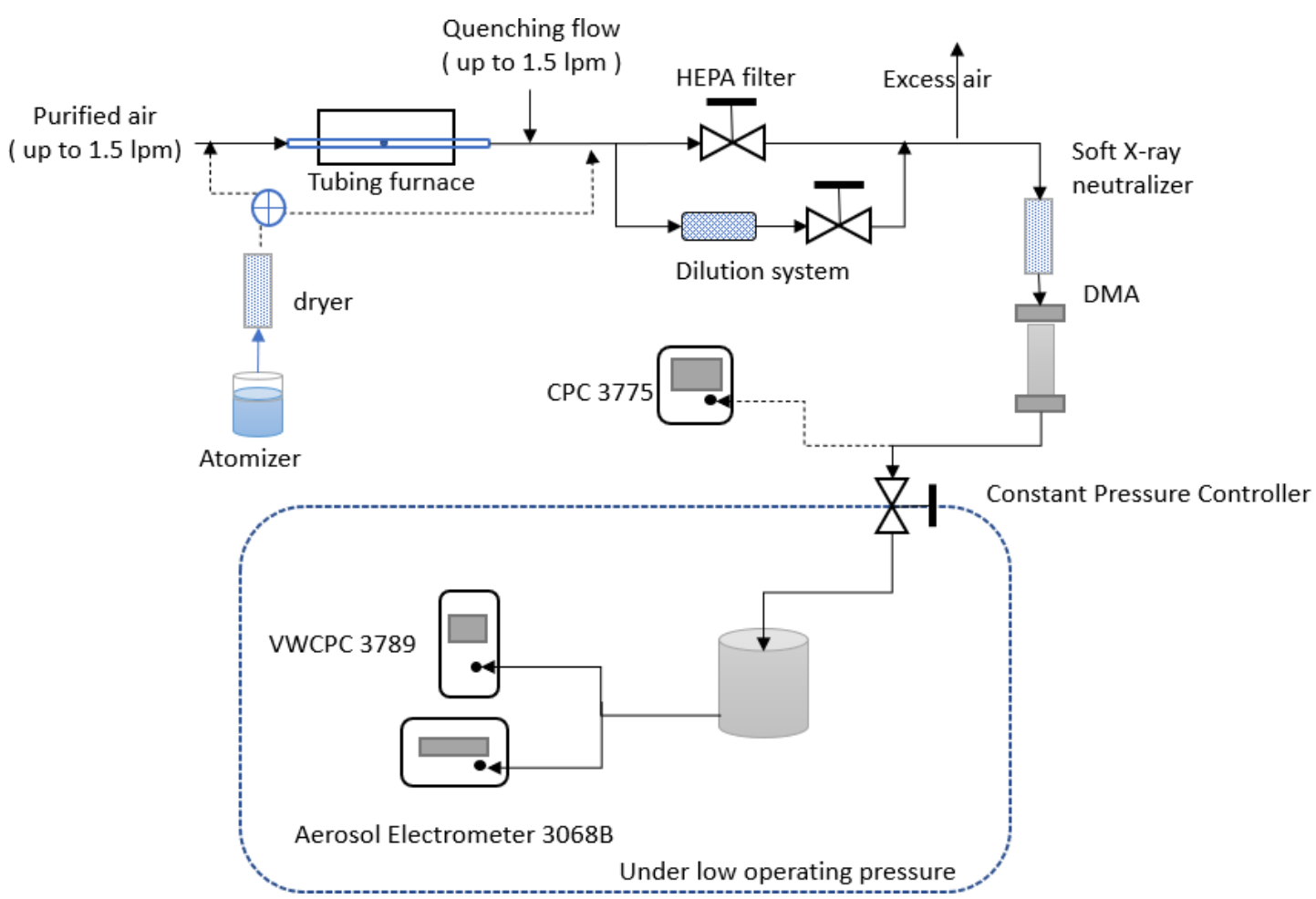

Figure 2. Schematic of the vWCPC 3789 sensors and flow system under the low-pressure testing.

the conditioner can obtain higher supersaturation and smaller activation size.

Furthermore, shifting the $70^{\circ}$ temperature difference window by decreasing the conditioner temperature (from 9 to $1^{\circ}$ ) further reduces the activation size. In addition, the Hering et al. paper pointed out that the final droplet size decreases from around 4.5 to $2.5 \mu \mathrm{m}$ with the increase in the aerosol inlet flow rate from 0.4 to $1.5 \mathrm{~L} \mathrm{~min}^{-1}$. This behavior is consistent with the Bian et al. result, which shows that when the flow rate increased by a factor of 2.5 , the final size decreased by $43 \%$.

\section{Results and discussion}

\subsection{Pressure dependence of the vWCPC 3789 counting efficiency}

The CPC counting efficiency is defined by the ratio of the particle number concentration measured by the vWCPC 3789 and the reference particle number concentration measured by the A.E. Multiple charged particles induce a reading error in the reference particle number concentration. This error is negligible for particle sizes less than $70 \mathrm{~nm}$ compared to other experimental errors (Herman et al., 2007; Hermann and Wiedensohler, 2001). For aerosol particles larger than $70 \mathrm{~nm}$, an empirical correction was estimated using the size distribution of the generated aerosol, the aerosol charging distribution (Tigges et al., 2015), and the particle loss through the constant pressure inlet, which can be estimated based on the total number concentration difference measured by the CPC 3775 and vWCPC 3789.

Using the low-pressure testing setup shown in Fig. 2, the counting efficiency of a vWCPC 3789 was measured between 500 and $920 \mathrm{hPa}$ for AS particles of 15, 25, and $100 \mathrm{~nm}$ (mobility diameter). The aerosol concentrations in this test were maintained in the range $2 \times 10^{4}-4 \times 10^{4} \mathrm{~cm}^{-3}$. The obtained counting efficiencies for the manufacturer's $7 \mathrm{~nm}$ cutoff setting are shown in Fig. 3. The conditioner, initiator, and moderator temperatures were 30,59 , and $10^{\circ}$ under this setting.

During the testing, the temperature variations in the conditioner and moderator were less than $\pm 0.5^{\circ}$. For the " $7 \mathrm{~nm}$ " temperature setting, the initiator temperature has a variation of $\pm 1^{\circ}$. The $y$-axis error bar indicates the standard deviation of the counting efficiency averaged over $\sim 5 \mathrm{~min}$ of sampling time at a $1 \mathrm{~Hz}$ sampling rate. Figure 3 shows that the counting efficiencies decreased with the decrease in the operating pressure around $700 \mathrm{hPa}$. The decreases became significant and larger than $10 \%$ when the operating pressure was lower than $600 \mathrm{hPa}$.

Based on the $\kappa$-Köhler theory and the supersaturation (saturation ratio minus 1) estimated at the centerline of a threestage chamber in Fig. S2, ammonium sulfate particles larger than $9.7 \mathrm{~nm}$ should all be activated when the saturation ratio is larger than 1.05 , even if we assume that the supersaturation 


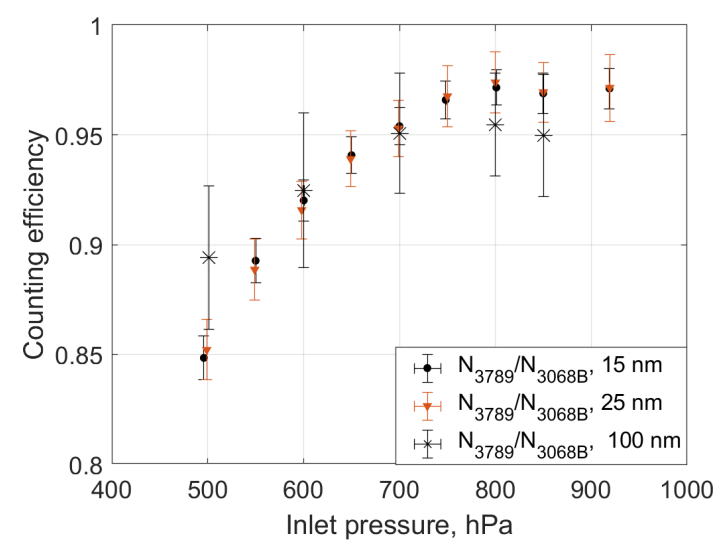

Figure 3. The vWCPC 3789 counting efficiency as a function of the inlet operation pressure at TSI standard conditions: $T_{\text {cond }}=30^{\circ}$, $T_{\text {ini }}=59^{\circ}$, and $T_{\text {mod }}=10^{\circ} \mathrm{C} . N_{3789} / N_{3068 B}$ is the total number concentration ratio between the $\mathrm{VWCPC}$ and the electrometer.

profile near the wall has an $85 \%$ drop from the centerline condition. Thus, the low counting efficiency under the lowpressure operation condition is not limited by aerosol activation.

Previous simulation studies show that the centerline saturation ratio is not sensitive to the wall temperature of the moderator (Bian et al., 2020; Hering et al., 2014). However, under the low-pressure condition (e.g., $500 \mathrm{hPa}$ ), the saturation profile peaked earlier but lower than the saturation profile under the standard condition $(1000 \mathrm{hPa})$, as shown in Fig. S2. Also, decreasing the conditioner temperature (while maintaining the same temperature difference between the initiator and the conditioner) provided higher saturation ratios in the initiator and more water vapor for particle growth, which is also consistent with the previous growth tubing simulation (Bian et al., 2020). Thus, we examine the temperature effect on the vWCPC 3789 performance under the lowpressure condition in the following section. Furthermore, with the aid of the simulation, we study how to overcome the counting efficiency decrease experimentally.

\subsection{Simulation-aided investigation of the pressure dependence of the vWCPC 3789 counting efficiency at different conditioner temperatures}

The simulated saturation profiles of a three-stage growth tube at different operation pressure (1000 and $500 \mathrm{hPa})$ for three different conditioner temperatures $\left(30,27\right.$, and $\left.24^{\circ}\right)$, all with an initiator temperature of $59^{\circ} \mathrm{C}$ and moderator temperature of $10^{\circ} \mathrm{C}$, are presented in Fig. 4 . The predicted droplet size evolution along the growth tube of this vWCPC 3789 at different operation pressures $(1000$ and $500 \mathrm{hPa})$ under three conditioner temperatures $\left(30,27\right.$, and $\left.24^{\circ}\right)$ is included in Fig. 5. In most water-based CPCs, the aerosol particle growth is initiated by the temperature rise from the conditioner to the initiator. The growth rate is modulated by the temperature de- crease from the initiator and the moderator. The maximum saturation ratio calculated at the centerline usually occurs downstream of the initiator exit due to the water vapor diffusion delay. However, in Fig. 4, we observe a double-peaked saturation ratio profile that appeared for three different conditioner temperature settings under both operation pressures $(1000$ and $500 \mathrm{hPa})$. The maximum saturation peak occurs inside the moderator under most simulated conditions, except when the operation pressure decreases to $500 \mathrm{hPa}$ at the conditioner temperature of $24^{\circ}$, at which the highest saturation peak occurs inside the initiator. Under the standard pressure, this configuration has the advantage that the peak extends close to the wall, resulting in high counting efficiency and a sharp lower cut-off size, as shown in Fig. 5. With the decrease in the operating pressure, the saturation peaks showed a substantial reduction, which was also associated with both the lower cut-off size increasing in Fig. 4 and the growing droplet size decreasing in Fig. 5. When the conditioner temperature was 27 or $30^{\circ}$, with decreasing of the operating pressure from 1000 to $500 \mathrm{hPa}$, one $8 \mathrm{~nm}$ seed particle grew to a smaller size ( $\sim 40 \%$ reduction in the droplet diameter) regardless of whether the particle entered the growth tube in the centerline or near the wall. The seed particles entering the centerline of a growth tube got activated in the initiator. A delay of the activation occurred for the seed particles entering the growth tube away from the centerline, and those particles at $75 \%$ of radius started growing in the moderator.

Guided by the above analysis and the observations, we maintained the temperature settings in the initiator at $59^{\circ} \mathrm{C}$ and moderator at $10^{\circ} \mathrm{C}$ and varied the conditioner temperatures by $3^{\circ}$. The aerosol particle concentrations for $100 \mathrm{~nm}$ size-selected particles were maintained at around $6 \times 10^{3}\left(\mathrm{~cm}^{-3}\right)$ in this study to avoid concentration effects (more discussion in Sect. 3.3). Under each conditioner temperature, we examined the impact of the operating pressure on the aerosol particle growth inside the three-stage growth tube through the simulation (shown in Figs. 4, 5, and S2) and on the vWCPC 3789 counting efficiency change through the experiment (as shown in Fig. 6). When the conditioner temperature was set at 30 or $33^{\circ}$, the counting efficiency dropped as the inlet pressure was lowered from 1000 to $500 \mathrm{hPa}$. However, when the conditioner temperature was decreased to 27 or $24^{\circ}$, we did not observe a noticeable decrease in the counting efficiency with the operating pressure decrease.

The experimental results suggest that increasing the temperature difference between the conditioner and the initiator affected the vWCPC 3789 counting efficiency. As shown in Fig. 6, the counting efficiencies of the $T_{\text {cond }}=27^{\circ}$ setting were maintained close to 1 when the operating pressure dropped to $500 \mathrm{hPa}$. Although we present data with $100 \mathrm{~nm}$ particles in Fig. 6, we observed a similar trend with particles down to $15 \mathrm{~nm}$ (Fig. S3). This observation suggests that the low counting efficiency observed in Fig. 3 was not mainly caused by the particle loss inside the instruments. Figure 5 suggests that although the second saturation peak in the mod- 

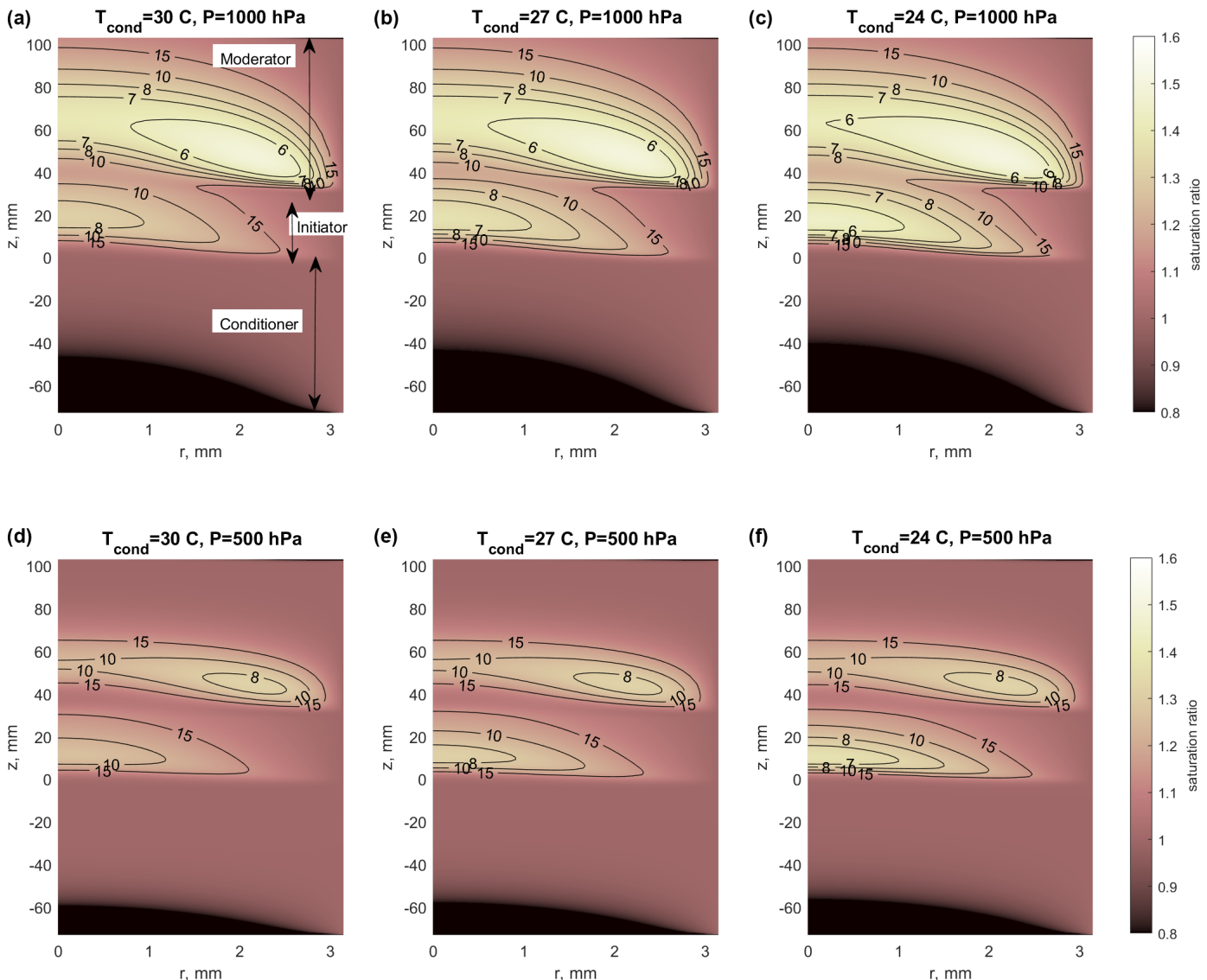

Figure 4. Simulation of the CPC 3789 saturation ratio profiles at $1000 \mathrm{hPa}(\mathbf{a}-\mathbf{c})$ and at $500 \mathrm{hPa}(\mathbf{d}-\mathbf{f})$ under the different conditioner temperatures $\left(30,27\right.$, and $\left.24^{\circ}\right)$ with the initiator temperature at $59^{\circ}$ and the moderator temperature at $10^{\circ}$. The color bar indicates the humidity (the saturation ratio) change inside the three-stage growth tube. The contour line indicates the saturation ratio necessary to activate $6,7,8,10$, and $15 \mathrm{~nm}$ seed particles. $r$ is the distance from the centerline. $z$ is the distance from the entrance of the initiator, which means that the conditioner is from -73 to $0 \mathrm{~mm}$.
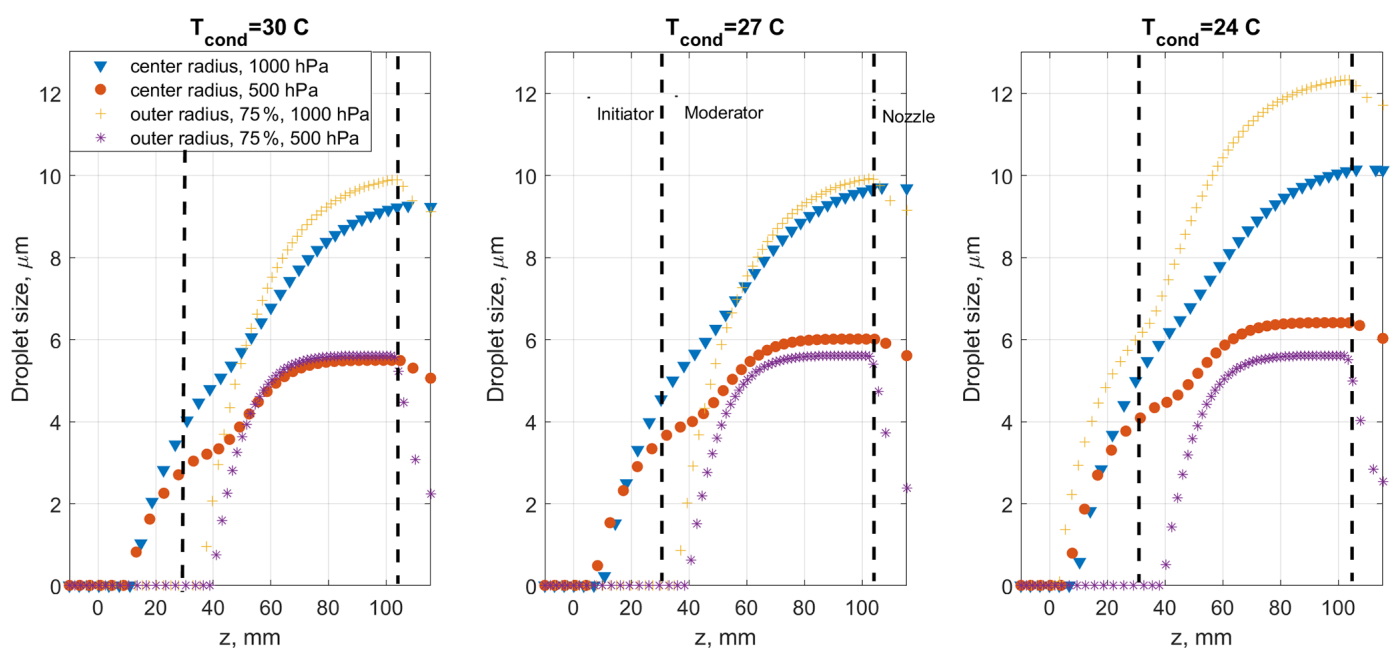

Figure 5. Predicted droplet size evolution along the growth tube (at centerline or $75 \%$ of the inner tubing radius) of the vWCPC 3789 under the different conditioner temperatures $\left(30,27\right.$, and $\left.24^{\circ}\right)$ with the initiator temperature at $59^{\circ}$ and the moderator temperature at $10^{\circ}$. Starting particle size $8 \mathrm{~nm}$. The dashed lines indicate the starting and ending locations of the moderator. 


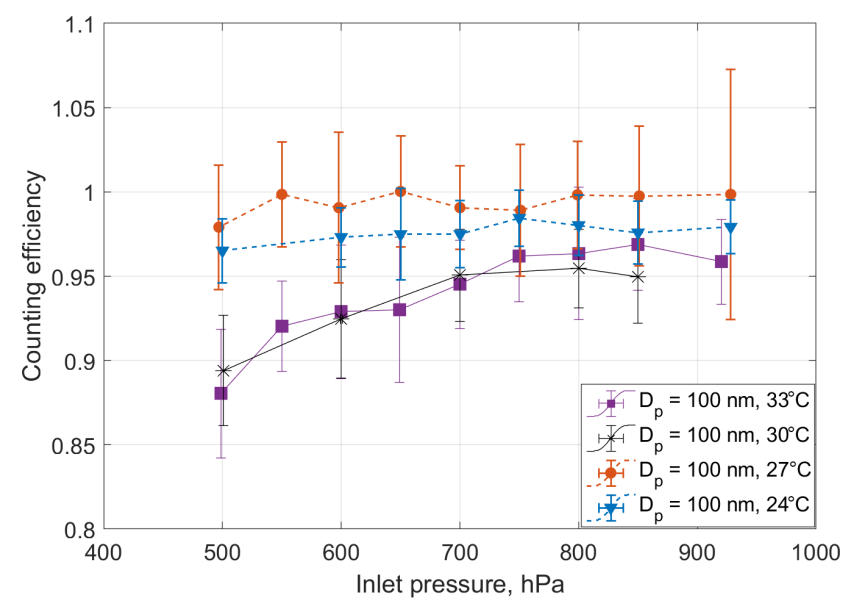

Figure 6. The vWCPC 3789 counting efficiency as a function of the inlet operation pressure at four conditioner temperatures of $T_{\text {cond }}=24,27,30$, and $33^{\circ} \mathrm{C}\left(T_{\text {ini }}=59^{\circ} \mathrm{C}, T_{\text {mod }}=10^{\circ} \mathrm{C}\right)$.

erator activated the seed particles and is capable of maintaining droplet growth, about $10 \%$ of particles may not grow large enough to be detected in the optical chamber. Therefore, the counting efficiency is more susceptible to the first peak of the supersaturation profile in the initiator. In addition, the absolute saturation also set the threshold for successfully operating this vWCPC 3789 under lower pressure. Combining the observations from Figs. 6 and S3 and the simulation in Figs. 4 and 5, when the simulated saturation is over 1.3, the counting efficiency is maintained close to 1 for aerosol particles larger than $8 \mathrm{~nm}$ under low-pressure conditions (500$920 \mathrm{hPa}$ ). We also noticed that the counting efficiency curve is slightly lower when operating the conditioner at $24^{\circ}$ than when the conditioner was set to $27^{\circ}$. That is possibly due to the high supersaturation profile inside the three-stage tube, leading to larger droplets, especially close to the wall, and increased loss at the tubing wall and through the focusing nozzle.

\subsection{Particle concentration and pressure effects on droplet size and vWCPC 3789 counting efficiency}

In typical operation, the manufacturer reports that the singleparticle counting concentration is maintained up to a concentration of $2 \times 10^{5}\left(\mathrm{~cm}^{-3}\right)$. The reported "pulse height" by a vWCPC 3789 is not the pulse height value produced by the light-scattering signal. It is a calculated parameter, which indicates the fraction of the particle population generating an acceptably high pulse. The manufacturer's manual states that the pulse height is above 0.9 for moderate concentrations $\left(\sim 10-5000 \mathrm{~cm}^{-3}\right)$. Thus, we examined if this concentration threshold would hold under low-pressure conditions. For $100 \mathrm{~nm}$ particles, we observed that the pulse height decreases with the decrease in the operating pressure, as shown in Fig. 7a. When the operation pressure decreased from 550 to $500 \mathrm{hPa}$, the pulse height decreased from above $90 \%$ to around $80 \%$, as shown in Fig. 7a. Meanwhile, for $100 \mathrm{~nm}$ aerosol particles, the threshold concentration $\left(N_{\text {mea }}\right.$, under $500 \mathrm{hPa}$ ) for a $10 \%$ reduction with the pulse height values was about $1 \times 10^{4}\left(\mathrm{~cm}^{-3}\right)$, as shown in Fig. $7 \mathrm{~b}$. When the aerosol concentration was larger than $2 \times 10^{4}\left(\mathrm{~cm}^{-3}\right)$, decreasing the pressure affected the measured aerosol concentration more significantly, as shown in Fig. S6b. Comparing the pulse height curves, while the conditioner temperature operated at 24 and $30^{\circ}$, Fig. S6a shows that the $30^{\circ}$ case suffered more water vapor shortage while decreasing the operating pressure. Additionally, Fig. S6 shows there is no significant difference between the measured $10 \%$ reduction threshold between 20 and $100 \mathrm{~nm}$ particles when the particle concentration is less than $1 \times 10^{4}\left(\mathrm{~cm}^{-3}\right)$. This observation was consistent with the simulated $10 \%$ reduction of $s$ and $D_{p}$ that happened with $N_{7 \mu \mathrm{m}} \sim 8.5 \times 10^{3}\left(\mathrm{~cm}^{-3}\right)$, as discussed in the Supplement (shown in Fig. S4). Moreover, it indicates that we can monitor the pulse height value to detect the undercounting issue. When the pulse height was less than $80 \%$, the measured aerosol concentration by vWCPC 3789 was about $10 \%$ less than the aerosol concentration measured by the electrometer.

\subsection{Effect of particle chemical composition on the vWCPC 3789 counting efficiency}

We examined the counting efficiency of the vWCPC 3789 using aerosol particles with different chemical compositions and water solubility, as shown in Table S1. During this test, $100 \mathrm{~nm}$ aerosol particles were atomized and dried from the ammonium sulfate, sucrose, humic acid, and PSL solutions or suspensions before entering the DMA, as shown in Fig. 2. We chose two types of $100 \mathrm{~nm}$ aerosol particles: waterinsoluble particles (such as oleic acid, humic acid particles, and PSL) and highly hydrophilic ammonium sulfate and sucrose particles. Running the $100 \mathrm{~nm}$ particles under different operating pressures, we got the counting efficiencies close to 1 for PSL, humic acid, and AS particles, as shown in Fig. 8 . However, the counting efficiencies of the oleic acid and PSL particles showed more significant uncertainty than that of the ammonium sulfate particles. We could not achieve a reliable curve of the oleic acid particles because oleic acid particles evaporated under low-pressure conditions and caused a significant variation in the number concentration and size distribution of size-selected particles. We noticed that the PSL particle curve has more substantial variation compared to the other aerosol particles. The particle surface is very hydrophobic, and the droplet growth process will be affected by the remaining water or surfactant on the particle surface. The counting efficiency of humic acid particles was slightly lower than that of AS aerosol particles, which could likely be explained by the light-absorbing properties of humic acid. The counting efficiency of sucrose is significantly lower than the counting efficiency of AS (10\% lower). This observation is 

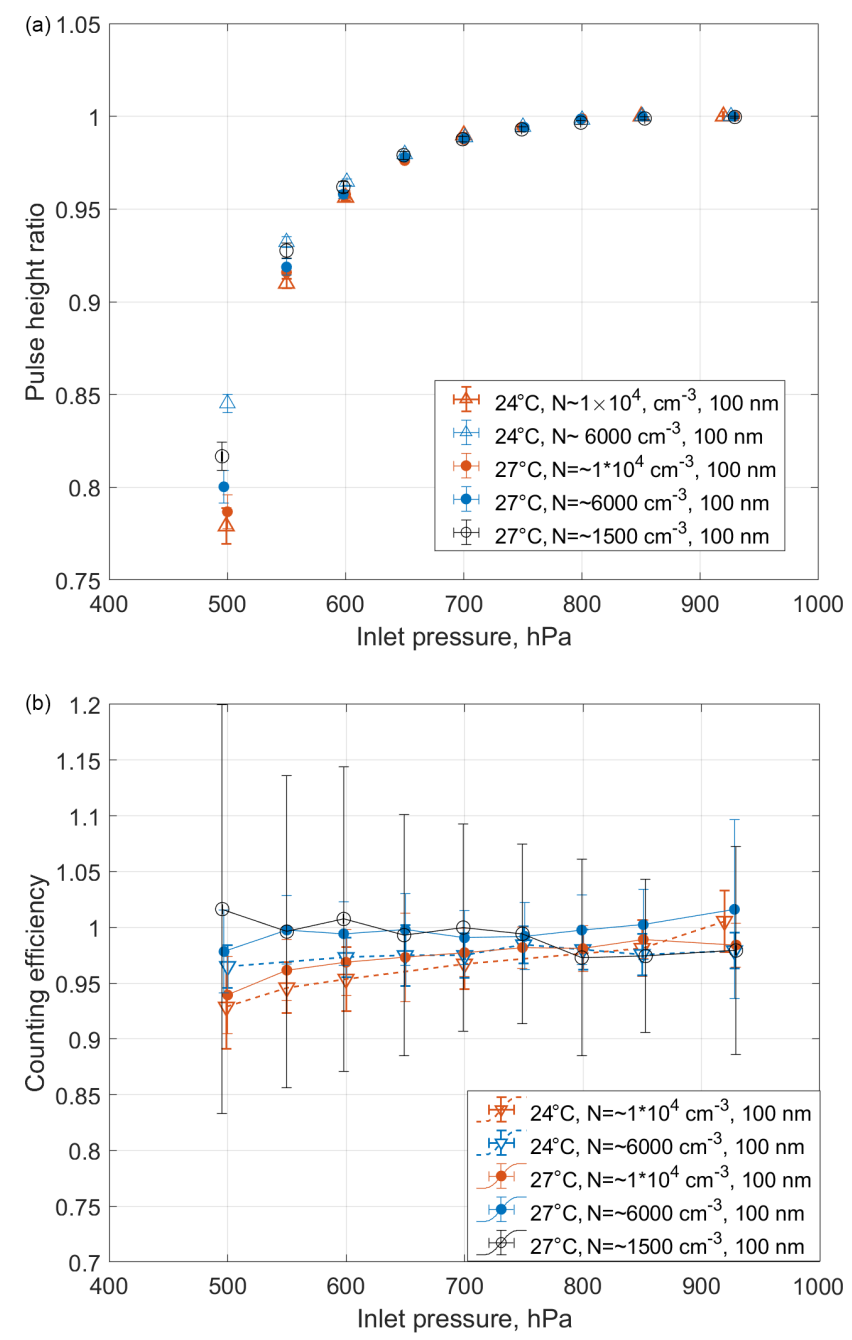

Figure 7. The water depletion due to the aerosol number concentration, as illustrated by (a) the pulse height generated in the optical detector and (b) the counting efficiency as a function of the inlet pressure. Results are shown with the conditioner temperatures set at 24 and $27^{\circ} \mathrm{C}$.

consistent with a previous study (Hering et al., 2017). One possible explanation is that the chemical similarity between the seed particle material and the working fluid also affects the detection efficiency of the vWCPC 3789 (Wlasits et al., 2020).

\subsection{Temperature dependence of the vWCPC 3789 cut-off size}

For the butanol-based CPCs, such as TSI CPC 7610, the CPC cut-off size is strongly influenced by the temperature difference between the saturator and condenser (Hermann and Wiedensohler, 2001; Kangasluoma and Attoui, 2019). Typically, the cut-off size decreases with the increase in the temperature difference (Hermann et al., 2005; Hermann and Wiedensohler, 2001). We observed that this trend held

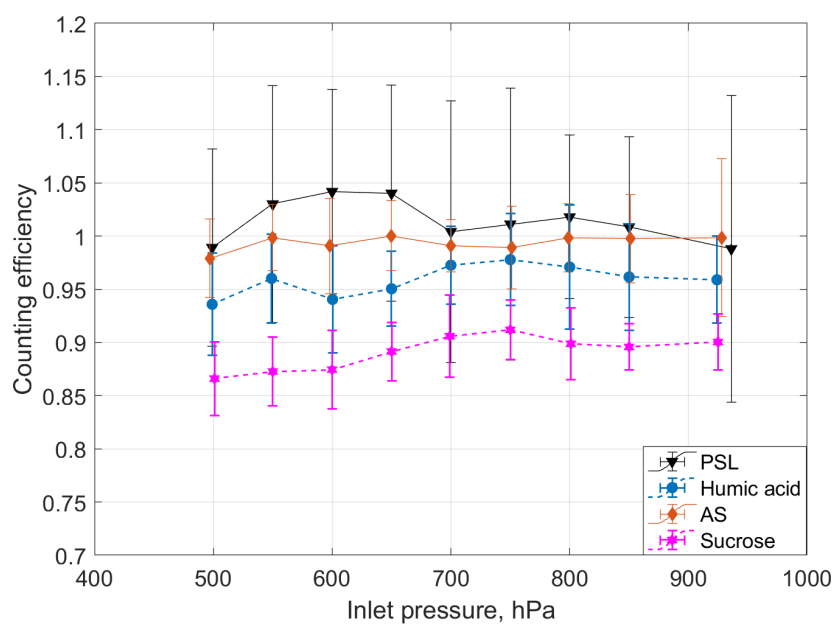

Figure 8. The vWCPC 3789 counting efficiency at different operating pressure with four different types of $100 \mathrm{~nm}$ aerosol particles (PSL, humic acid, AS, and sucrose) when the temperature conditions are $T_{\text {cond }}=27^{\circ}$ and $T_{\text {ini }}=59^{\circ}$.

well for the vWCPC 3789 using AS particles, as shown in Fig. 9. The temperature effect on the counting efficiency of the vWCPC 3789 under low-pressure conditions is also presented in Fig. 9. With the decrease in the conditioner temperature, the temperature difference between the initiator and the conditioner increases. As expected, the cut-off size slightly moved to lower than $7 \mathrm{~nm}$. However, with the decrease in the operating pressure, the cut-off size increased slightly. Under two conditioner temperatures $\left(24\right.$ and $\left.27^{\circ}\right)$, the cut-off size was maintained between 6 and $8 \mathrm{~nm}$, even when the pressure dropped to $500 \mathrm{hPa}$. Thus, both settings are suitable for airborne operations up to $5.5 \mathrm{~km}$ with a $7 \mathrm{~nm}$ cut-off size. Note that the counting efficiency curve from TSI at $30^{\circ}$ was derived and fitted using an AS particle classified by a custommade different mobility analyzer (using an aerosol-to-sheath flow rate ratio of $1: 100$ ) under a near-sea-level pressure (W1asits et al., 2020). As a result of operation over a much wider pressure range, the cut-off curve derived by this study is less sharp than for the TSI standard settings.

\section{Conclusions}

This study discusses the modification and characterization of the versatile water CPC (TSI 3789) operating under lowpressure conditions. A commercially available vWCPC 3789 was modified to report the inlet operating pressure during airborne operation. The vWCPC 3789 counting efficiency was characterized as a function of operating pressure $(500-920 \mathrm{hPa})$ for different conditioner temperatures (24$33^{\circ}$ ) with the factory settings for the initiator and moderator temperatures $\left(59\right.$ and $10^{\circ}$ ). The vWCPC 3789 with all manufacturer settings (i.e., conditioner temperature of $30^{\circ}$ ) worked as expected under the standard ambient condition 

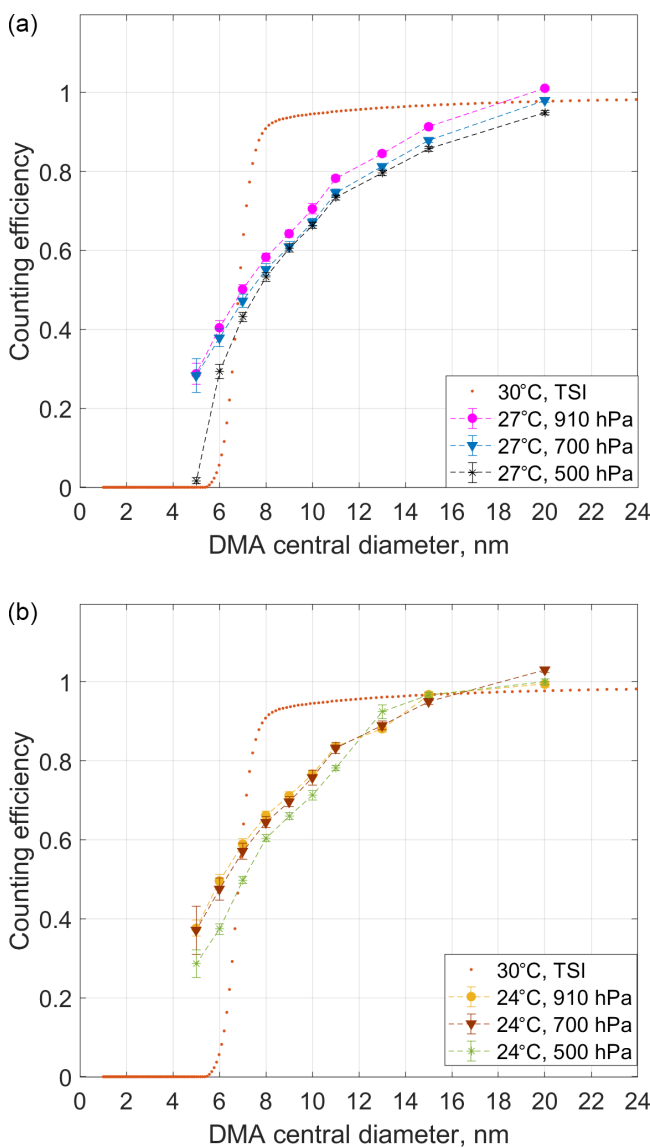

Figure 9. The vWCPC 3789 counting efficiency changes as a function of the different operating pressures $(500,700$, and $910 \mathrm{hPa})$ using AS particles when the initiator temperature is $59^{\circ}$ and the moderator temperature is $10^{\circ}$ at two different conditioner temperatures of (a) $T_{\text {cond }}=27$ and (b) $T_{\text {cond }}=24^{\circ}$.

(i.e., $1 \mathrm{~atm}$ ). However, under low-pressure conditions, the counting efficiency of the vWCPC 3789 operated with the factory settings decreased with the decrease in the operating pressure, especially when the operating pressure was below $700 \mathrm{hPa}$. Although not being able to fully explain the decrease in counting efficiency, numerical simulations and the dimensionless analysis show that the peak saturation ratio at $500 \mathrm{hPa}$ is significantly lower than that at $1000 \mathrm{hPa}$ but occurs closer to the entrance of the initiator. At the same operation pressure, the simulated peak saturation ratio increases with decreasing conditioner temperature. Aided by the simulation results, we examined the effect of conditioner temperature on the counting efficiency and identified an optimal conditioner temperature setting of $27^{\circ}$ for operating the vWCPC 3789 over a range of pressure levels. Additionally, decreasing the conditioner temperature to $27^{\circ}$ did not significantly change the lower cut-off size of $7 \mathrm{~nm}$ for the vWCPC 3789. Thus, for airborne operation down to $500 \mathrm{hPa}$ ( $\sim 6000 \mathrm{~m}$ above sea level), we recommend operating the vWCPC 3789 with the conditioner temperature setting of $27^{\circ}$. We also observed that the conditioner temperature has a more pronounced effect on the vWCPC's counting efficiency curve than the operating pressure. A simplified water depletion estimation suggests a $10 \%$ reduction of the saturation ratio $(s)$ and the droplet diameter $\left(D_{p}\right)$ under a pressure of $500 \mathrm{hPa}$ when $N_{7 \mu \mathrm{m}} \sim 8.5 \times 10^{3}\left(\mathrm{~cm}^{-3}\right)$. The impact of aerosol number concentration on the pulse height reported by the vWCPC 3789 was examined. Similar to the counting efficiency, the pulse height exhibits a decreasing trend with decreasing operating pressure. When the pulse height was larger than $80 \%$ and the particle concentration was less than $1 \times 10^{4}\left(\mathrm{~cm}^{-3}\right)$, a $10 \%$ reduction in the measured concentration was observed for 20 and $100 \mathrm{~nm}$ particles. This observation suggests that the reported pulse height could be used to monitor the potential bias caused by high particle concentration. The chemical composition of aerosol also contributes up to $20 \%$ uncertainty to the counting efficiency of CPC, and this uncertainty shows no significant trend with the operating pressure changes when the $\mathrm{CPC}$ is operated with the conditioner temperature at $27^{\circ}$.

The main advantage of vWCPC 3789 is the non-toxic and non-flammable working fluid. Additionally, water has a smaller calculated Kelvin diameter than other working fluids, which means a water-based CPC could lead to a lower size detection limit (Magnusson et al., 2003a). However, for the airborne operation, the elevation will reduce the CPC operating pressure, which limits the highest temperature we could choose for the initiator to push the detection limit lower. Thus, further studies are needed to determine how to reduce the lower detection limit of the vWCPC 3789 under various ambient pressures.

Data availability. The CPC data in the study are available upon reasonable request to Fan Mei (fan.mei@pnnl.gov).

Supplement. The supplement related to this article is available online at: https://doi.org/10.5194/amt-14-7329-2021-supplement.

Author contributions. FM, MSP, SH, and JW designed the research. FM carried out the measurements. FM led the analyses, and SS and GL led the simulation. FM led the writing, with significant input from SH and JW as well as further input from all other authors. BS and JT acquired the financial support for the project leading to this publication. MH provided suggestions during the experimental design. SH, JW, and BS provided suggestions on the revision.

Competing interests. Susanne Hering and Maynard Havlicek have a commercial interest in the success of the vWCPC instrument. 
Disclaimer. Publisher's note: Copernicus Publications remains neutral with regard to jurisdictional claims in published maps and institutional affiliations.

Acknowledgements. This work has been supported by the Office of Biological and Environmental Research (OBER) of the U.S. Department of Energy (DOE) as part of the Atmospheric Radiation Measurement (ARM) and Atmospheric System Research (ASR) Programs. Battelle operates the Pacific Northwest National Laboratory (PNNL) for the DOE under contract DE-A06-76RLO 1830. We sincerely appreciate the valuable discussion with Andrea Tiwari (TSI), Oliver Bischof (TSI), and Justin Koczak (TSI).

Review statement. This paper was edited by Charles Brock and reviewed by two anonymous referees.

\section{References}

Anderson, E. L., Turnham, P., Griffin, J. R., and Clarke, C. C.: Consideration of the aerosol transmission for COVID-19 and public health, Risk Anal., 40, 902-907, 2020.

Bian, J. J., Gui, H. Q., Xie, Z. B., Yu, T. Z., Wei, X. L., Wang, W. Y., and Liu, J. G.: Simulation of three-stage operating temperature for supersaturation water-based condensational growth tube, J. Environ. Sci., 90, 275-285, 2020.

Biswas, S., Fine, P. M., Geller, M. D., Hering, S. V., and Sioutas, C.: Performance evaluation of a recently developed water-based condensation particle counter, Aerosol Sci. Tech., 39, 419-427, 2005

Brock, C. A., Williamson, C., Kupc, A., Froyd, K. D., Erdesz, F., Wagner, N., Richardson, M., Schwarz, J. P., Gao, R.-S., Katich, J. M., Campuzano-Jost, P., Nault, B. A., Schroder, J. C., Jimenez, J. L., Weinzierl, B., Dollner, M., Bui, T., and Murphy, D. M.: Aerosol size distributions during the Atmospheric Tomography Mission (ATom): methods, uncertainties, and data products, Atmos. Meas. Tech., 12, 3081-3099, https://doi.org/10.5194/amt12-3081-2019, 2019.

Curtius, J.: Nucleation of atmospheric aerosol particles, Cr. Phys., 7, 1027-1045, 2006.

Franklin, L. M., Bika, A. S., Watts, W. F., and Kittelson, D. B.: Comparison of water and butanol based CPCs for examining diesel combustion aerosols, Aerosol Sci. Tech., 44, 629-638, 2010

Friedlander, S.: The characterization of aerosols distributed with respect to size and chemical composition, J. Aerosol Sci., 1, 295307, 1970

Friedlander, S.: The characterization of aerosols distributed with respect to size and chemical composition - II. Classification and design of aerosol measuring devices, J. Aerosol Sci., 2, 331-340, 1971.

Hakala, J., Manninen, H. E., Petaja, T., and Sipila, M.: Counting efficiency of a TSI environmental particle counter monitor model 3783, Aerosol Sci. Tech., 47, 482-487, 2013.

Hering, S. V., Stolzenburg, M. R., Quant, F. R., Oberreit, D. R., and Keady, P. B.: A laminar-flow, water-based condensation particle counter (WCPC), Aerosol Sci. Tech., 39, 659-672, 2005.
Hering, S. V., Spielman, S. R., and Lewis, G. S.: Moderated, waterbased, condensational particle growth in a laminar flow, Aerosol Sci. Tech., 48, 401-408, 2014.

Hering, S. V., Lewis, G. S., Spielman, S. R., Eiguren-Fernandez, A., Kreisberg, N. M., Kuang, C. A., and Attoui, M.: Detection near 1-nm with a laminar-flow, water-based condensation particle counter, Aerosol Sci. Tech., 51, 354-362, 2017.

Hering, S. V., Lewis, G. S., Spielman, S. R., and EigurenFernandez, A.: A MAGIC concept for self-sustained, waterbased, ultrafine particle counting, Aerosol Sci. Tech., 53, 63-72, 2019.

Hermann, M. and Wiedensohler, A.: Counting efficiency of condensation particle counters at low-pressures with illustrative data from the upper troposphere, J. Aerosol Sci., 32, 975-991, 2001.

Hermann, M., Adler, S., Caldow, R., Stratmann, F., and Wiedensohler, A.: Pressure-dependent efficiency of a condensation particle counter operated with FC-43 as working fluid, J. Aerosol Sci., 36, 1322-1337, 2005.

Hermann, M., Wehner, B., Bischof, O., Han, H. S., Krinke, T., Liu, W., Zerrath, A., and Wiedensohler, A.: Particle counting efficiencies of new TSI condensation particle counters, J. Aerosol Sci., 38, 674-682, 2007.

Iida, K., Stolzenburg, M. R., McMurry, P. H., Smith, J. N., Quant, F. R., Oberreit, D. R., Keady, P. B., Eiguren-Fernandez, A., Lewis, G. S., Kreisberg, N. M., and Hering, S. V.: An ultrafine, waterbased condensation particle counter and its evaluation under field conditions, Aerosol Sci. Tech., 42, 862-871, 2008.

Iida, K., Stolzenburg, M. R., and McMurry, P. H.: Effect of working fluid on sub-2 $\mathrm{nm}$ particle detection with a laminar flow ultrafine condensation particle counter, Aerosol Sci. Tech., 43, 81-96, 2009.

Jeong, C. H. and Evans, G. J.: Inter-comparison of a fast mobility particle sizer and a scanning mobility particle sizer incorporating an ultrafine water-based condensation particle counter, Aerosol Sci. Tech., 43, 364-373, 2009.

Kaminsky, J. A., Gaskin, E. A. L. M., Matsuda, M., and Miguel, A. H.: In-cabin commuter exposure to ultrafine particles on commuter roads in and around Hong Kong's Tseung Kwan O tunnel, Aerosol Air Qual. Res., 9, 353-357, 2009.

Kangasluoma, J. and Attoui, M.: Review of sub-3 nm condensation particle counters, calibrations, and cluster generation methods, Aerosol Sci. Tech., 53, 1277-1310, 2019.

Kangasluoma, J., Cai, R. L., Jiang, J. K., Deng, C. J., Stolzenburg, D., Ahonen, L. R., Chan, T., Fu, Y. Y., Kim, C., Laurila, T. M., Zhou, Y., Dada, L., Sulo, J., Flagan, R. C., Kulmala, M., Petaja, T., and Lehtipalo, K.: Overview of measurements and current instrumentation for $1-10 \mathrm{~nm}$ aerosol particle number size distributions, J. Aerosol Sci., 148, 105584, https://doi.org/10.1016/j.jaerosci.2020.105584, 2020.

Kangasluoma, J., Hering, S., Picard, D., Lewis, G., Enroth, J., Korhonen, F., Kulmala, M., Sellegri, K., Attoui, M., and Petäjä, T.: Characterization of three new condensation particle counters for sub-3 nm particle detection during the Helsinki CPC workshop: the ADI versatile water CPC, TSI 3777 nano enhancer and boosted TSI 3010, Atmos. Meas. Tech., 10, 2271-2281, https://doi.org/10.5194/amt-10-2271-2017, 2017.

Keller, A., Tritscher, T., and Burtscher, H.: Performance of waterbased CPC 3788 for particles from a propane-flame soot- 
generator operated with rich fuel/air mixtures, J. Aerosol Sci., 60, 67-72, 2013.

Kerminen, V. M., Chen, X. M., Vakkari, V., Petaja, T., Kulmala, M., and Bianchi, F.: Atmospheric new particle formation and growth: review of field observations, Environ. Res. Lett., 13, 103003, https://doi.org/10.1088/1748-9326/aadf3c, 2018.

Khlystov, A., Wyers, G., and Slanina, J.: The steam-jet aerosol collector, Atmos. Environ., 29, 2229-2234, 1995.

Kulmala, M., Vehkamaki, H., Petaja, T., Dal Maso, M., Lauri, A., Kerminen, V. M., Birmili, W., and McMurry, P. H.: Formation and growth rates of ultrafine atmospheric particles: a review of observations, J. Aerosol Sci., 35, 143-176, 2004.

Kupc, A., Bischof, O., Tritscher, T., Beeston, M., Krinke, T., and Wagner, P. E.: Laboratory characterization of a new nano-waterbased CPC 3788 and performance comparison to an ultrafine butanol-based CPC 3776, Aerosol Sci. Tech., 47, 183-191, 2013.

Kurten, A., Curtius, J., Nillius, B., and Borrmann, S.: Characterization of an automated, water-based expansion condensation nucleus counter for ultrafine particles, Aerosol Sci. Tech., 39, 1174-1183, 2005.

Lee, E. S., Polidori, A., Koch, M., Fine, P. M., Mehadi, A., Hammond, D., Wright, J. N., Miguel, A. H., Ayala, A., and Zhu, Y. F.: Water-based condensation particle counters comparison near a major freeway with significant heavy-duty diesel traffic, Atmos. Environ., 68, 151-161, 2013

Lewis, G. S. and Hering, S. V.: Minimizing concentration effects in water-based, laminar-flow condensation particle counters, Aerosol Sci. Tech., 47, 645-654, 2013.

Lighty, J. S., Veranth, J. M., and Sarofim, A. F.: Combustion aerosols: factors governing their size and composition and implications to human health, J. Air Waste Manage., 50, 1565-1618, 2000.

Liu, W., Kaufman, S. L., Osmondson, B. L., Sem, G. J., Quant, F. R., and Oberreit, D. R.: Water-based condensation particle counters for environmental monitoring of ultrafine particles, J. Air Waste Manage., 56, 444-455, 2006.

Magnusson, L.-E., Koropchak, J. A., Anisimov, M. P., Poznjakovskiy, V. M., and de la Mora, J. F.: Correlations for vapor nucleating critical embryo parameters, J. Phys. Chem. Ref. Data, 32, 1387-1410, 2003a.

Magnusson, L. E., Koropchak, J. A., Anisimov, M. P., Poznjakovskiy, V. M., and de la Mora, J. F.: Correlations for vapor nucleating critical embryo parameters, J. Phys. Chem. Ref. Data, 32, 1387-1410, 2003b.

McMurry, P. H.: The history of condensation nucleus counters, Aerosol Sci. Tech., 33, 297-322, 2000a.

McMurry, P. H.: A review of atmospheric aerosol measurements, Atmos. Environ., 34, 1959-1999, 2000b.

Mordas, G., Manninen, H. E., Petaja, T., Aalto, P. P., Hameri, K., and Kulmala, M.: On operation of the ultra-fine water-based CPC TSI3786 and comparison with other TSI models (TSI3776, TSI3772, TSI3025, TSI3010, TSI3007), Aerosol Sci. Tech., 42, 152-158, 2008.

Parsons, C. and Mavliev, R.: Design and characterization of a new, water-based, high sample-flow condensation nucleus counter, Aerosol Sci. Tech., 34, 309-320, 2001.

Petaja, T., Mordas, G., Manninen, H., Aalto, P. P., Hameri, K., and Kulmala, M.: Detection efficiency of a water-based TSI Conden- sation Particle Counter 3785, Aerosol Sci. Tech., 40, 1090-1097, 2006.

Pöschl, U.: Atmospheric aerosols: composition, transformation, climate and health effects, Angew. Chem. Int. Edit., 44, 7520-7540, 2005.

Schröder, F. and Ström, J.: Aircraft measurements of sub micrometer aerosol particles $(>7 \mathrm{~nm})$ in the midlatitude free troposphere and tropopause region, Atmos. Res., 44, 333-356, 1997.

Seifert, M., Tiede, R., Schnaiter, M., Linke, C., Mohler, O., Schurath, U., and Strom, J.: Operation and performance of a differential mobility particle sizer and a TSI 3010 condensation particle counter at stratospheric temperatures and pressures, J. Aerosol Sci., 35, 981-993, 2004.

Seinfeld, J. H., Bretherton, C., Carslaw, K. S., Coe, H., DeMott, P. J., Dunlea, E. J., Feingold, G., Ghan, S., Guenther, A. B., and Kahn, R.: Improving our fundamental understanding of the role of aerosol- cloud interactions in the climate system, P. Natl. Acad. Sci. USA, 113, 5781-5790, 2016.

Sem, G. J.: Design and performance characteristics of three continuous-flow condensation particle counters: a summary, Atmos. Res., 62, 267-294, 2002.

Sharma, N. L., Kuniyal, J. C., Singh, M., Sharma, P., Chand, K., Negi, A. K., Sharma, M., and Thakur, H. K.: Atmospheric ultrafine aerosol number concentration and its correlation with vehicular flow at two sites in the western Himalayan region: KulluManali, India, J. Earth Syst. Sci., 120, 281-290, 2011.

Spurny, K. R.: Atmospheric condensation nuclei P. J. Coulier 1875 and J. Aitken 1880 (historical review), Aerosol Sci. Tech., 32, 243-248, 2000.

Stolzenburg, M. R. and McMurry, P. H.: An ultrafine aerosol condensation nucleus counter, Aerosol. Sci. Tech., 14, 48-65, 1991.

Tigges, L., Wiedensohler, A., Weinhold, K., Gandhi, J., and Schmid, H. J.: Bipolar charge distribution of a soft X-ray diffusion charger, J. Aerosol Sci., 90, 77-86, 2015.

Tsang, H., Kwok, R., and Miguel, A. H.: Pedestrian exposure to ultrafine particles in Hong kong under heavy traffic conditions, Aerosol Air Qual. Res., 8, 19-27, 2008.

TSI Incoporated: Instrument manual, available at: https://tsi.com/products/ particle-counters-and-detectors/condensation-particle-counters/ versatile-water-based-condensation-particle-counter-3789/ (last access: February 2020), 2019.

Weigel, R., Hermann, M., Curtius, J., Voigt, C., Walter, S., Böttger, T., Lepukhov, B., Belyaev, G., and Borrmann, S.: Experimental characterization of the COndensation PArticle counting System for high altitude aircraft-borne application, Atmos. Meas. Tech., 2, 243-258, https://doi.org/10.5194/amt-2-243-2009, 2009.

Williamson, C., Kupc, A., Wilson, J., Gesler, D. W., Reeves, J. M., Erdesz, F., McLaughlin, R., and Brock, C. A.: Fast time response measurements of particle size distributions in the 3-60 nm size range with the nucleation mode aerosol size spectrometer, Atmos. Meas. Tech., 11, 3491-3509, https://doi.org/10.5194/amt11-3491-2018, 2018.

Wlasits, P. J., Stolzenburg, D., Tauber, C., Brilke, S., Schmitt, S. H., Winkler, P. M., and Wimmer, D.: Counting on chemistry: laboratory evaluation of seed-material-dependent detection efficiencies of ultrafine condensation particle counters, Atmos. Meas. Tech., 13, 3787-3798, https://doi.org/10.5194/amt13-3787-2020, 2020. 